\title{
Development of non-premixed porous inserted regenerative thermal oxidizer
}

\author{
Jun-chun ZHANG, Le-ming CHENG ${ }^{\dagger+}$, Cheng-hang ZHENG, Zhong-yang LUO, Ming-jiang NI \\ (State Key Laboratory of Clean Energy Utilization, Zhejiang University, Hangzhou 310027, China) \\ †E-mail: lemingc@zju.edu.cn \\ Received June 3, 2013; Revision accepted July 26, 2013; Crosschecked Aug. 20, 2013
}

\begin{abstract}
In this study, a porous inserted regenerative thermal oxidizer (PRTO) system was developed for a $125 \mathrm{~kW}$ industrial copper-melting furnace, due to its advantages of low $\mathrm{NO}_{x}$ emissions and high radiant efficiency. Zirconium dioxide $\left(\mathrm{ZrO}_{2}\right)$ ceramic foams were placed into the combustion zone of a regenerative thermal oxidizer (RTO). Different performance characteristics of the RTO and PRTO systems, including pressure drop, temperature distribution, emissions, and energy efficiency, were evaluated to study the effects of the porous inserts on non-premixed $\mathrm{CH}_{4}$ combustion. It was found that the PRTO system achieved a significant reduction in the $\mathrm{NO}_{x}$ emission level and a fuel saving of approximately $30 \%$ compared to the RTO system. It is most suitable for a lean combustion process at an equivalence ratio $<0.4$ with $\mathrm{NO}_{x}$ and $\mathrm{CO}$ emission levels within $0.002 \%-0.003 \%$ and $0.001 \%-0.002 \%$, respectively.
\end{abstract}

Key words: Porous media, Regenerative thermal oxidizer (RTO), Non-premixed $\mathrm{CH}_{4}$ combustion doi:10.1631/jzus.A1300198 Document code: A CLC number: TK16

\section{Introduction}

There is a growing demand in the energy industry for efficient and eco-friendly technologies due to environmental pollution and fossil-fuel depletion. Heat-circulating combustion processes, especially the alternating flow type, have been proven to be remarkable advances from both the technical and economic perspectives. These systems are known as regenerative thermal oxidizers (RTOs); in them, it is easy to obtain highly preheated combustion air and this leads to energy savings that make them attractive for combustion processes (Masashi and Toshiaki, 1998). However, the higher temperature of the preheated combustion air results in greater nitric oxide emissions; therefore, a reduction of $\mathrm{NO}_{x}$ emissions is required when these systems are used.

Numerous methods such as fuel/air staging,

\footnotetext{
${ }^{\ddagger}$ Corresponding author

(C) Zhejiang University and Springer-Verlag Berlin Heidelberg 2013
}

steam injection, and flue gas recirculation, etc., have been developed to reduce $\mathrm{NO}_{x}$ emissions, and substantial numerical and experimental investigations have been carried out (Suzukawa et al., 1997; Michael, 2001). The basic idea is to prevent the occurrence of hot spots in the flame, and thus reduce the formation of thermal $\mathrm{NO}_{x}$, which is dependent on the peak temperature. After it was recognized that solid materials provide the widest spectrum of thermal radiation, thereby reducing the emissions of $\mathrm{CO}$ and $\mathrm{NO}_{x}$ common pollutants, much research has been focused on porous media burner technology (Kamal and Mohamad, 2006; Wood and Harris, 2008). A subsequent decrease in the combustion temperature caused by the recirculation of heat away from the hot combustion products inhibits the formation of $\mathrm{NO}_{x}$; conversely, reduced temperatures in the combustion zone result in an incomplete combustion process that may increase $\mathrm{CO}$ and other unburned hydrocarbon emission levels. However, in the case of lean gas mixtures, many studies found that $\mathrm{CO}$ emissions tended to be very low (Smucker and 
Ellzey, 2004; Mathis and Ellzey, 2005; Mujeebu et al., 2011).

Previous studies have reported the applications of porous media burner technology in various fields (Mujeebu et al., 2009a; 2009b), especially their use as radiant burners where a radiant efficiency of up to 40\% was achieved (Howell et al., 1996) with lower pollutant emissions compared to swirl-stabilized combustor (Li et al., 2008). However, there are no reports of porous media burner technology being used in industrial regenerative burners. In this study, considering their advantages of low $\mathrm{NO}_{x}$ emissions and high radiant efficiency, a porous inserted regenerative thermal oxidizer (PRTO) system for copper melting was developed, and zirconium dioxide $\left(\mathrm{ZrO}_{2}\right)$ ceramic foams were inserted in the combustion zone for this purpose. Heat circulation in a diffusion combustion field is commonly used in large scale industrial applications; where nonpremixed flames will preferentially be used in combustion operations due to their controllability and safety factors. Thus, a PRTO system was designed for non-premixed combustion. This is a novel area of research as premixed flow conditions are normally used as the working conditions for porous media combustion systems; there have only been a few studies on non-premixed or partially-premixed combustion.

Kamal and Mohamad (2005) investigated the swirl effect on the enhancement of radiation flux from a porous burner operating with non-premixed flames and found that the $\mathrm{NO}_{x}$ emission level could reach below $0.001 \%$. Tarokh and Mohamad (2009) numerically studied the non-premixed combustion phenomena in a porous media. The results of this study demonstrated that combustion efficiency could be improved by the use of a porous media with a high thermal conductivity and emissivity as this reduced the $\mathrm{CO}$ and $\mathrm{NO}_{x}$ emission levels even when under non-premixed conditions. Charoensuk and Lapirattanakun (2011) and Muhad et al. (2011) investigated the performance of a partially-premixed liguefied petroleum gas (LPG) porous media burner, and found that $\mathrm{NO}_{x}$ and $\mathrm{CO}$ emission levels were reduced by $59 \%$ and $21 \%$, respectively, compared to the free flame combustion process. Wang et al. (2011) experimentally studied the temperature profiles characteristics of non-premixed combustion in porous media. Dobrego et al. (2001) reported a 2D two-temperature multi-component model for nonpremixed filtration combustion.

There is a need to study non-premixed filtration combustion under reciprocating flow conditions. The aim of this study was to examine the effects of porous inserts on regenerative thermal oxidizer (RTO) systems operating with non-premixed flames. In this study, experiments were performed to develop a PRTO system under reciprocating flow conditions in a $125 \mathrm{~kW}$ industrial copper-melting furnace, and the different performance characteristics of RTO and PRTO systems, including the pressure drop, temperature distribution, emissions, and energy efficiency, were evaluated.

\section{Experiments}

\subsection{Development of PRTO}

Fig. 1a shows an industrial copper-melting RTO heating system comprising of two ceramic honeycombs that are used as heat storage mediums in regenerators to preheated the combustion air temperature so that it is close to the furnace gas temperature, thus increasing the furnace productivity and saving a considerable amount of fuel. The melting process takes place in a crucible present in the middle of the furnace owing to the convection and radiation heat transfer between the combustion products and inner furnace walls. The furnace has a thermal input of $125 \mathrm{~kW}$ and a maximum copper-melting capacity of $750 \mathrm{~kg} / \mathrm{h}$. As shown in Fig. 2a, a diffusion flame is formed due to the preheated fresh air from the regenerator being mixed in the combustion zone with the fuel flow.

In this study, a PRTO was developed for the first time. As shown in Fig. 1b, the crucible furnace was filled with 10 PPI (pores per inch) ceramic foams (with $84 \%$ porosity) in the combustion zone. Initially, a $\mathrm{SiC}$ foam was used, but it was consumed as soon as there was a sudden increase in fuel composition. Then a $\mathrm{ZrO}_{2}$ foam was determined to be the best material that could withstand the high temperature of the preheated air combustion. Compared to the long flat flame in a conventional RTO system, the combustion zone in a PRTO system is stabilized in the finite element of the $\mathrm{ZrO}_{2}$ porous matrix as shown in 
Insulation Ceramic honeycomb EOr Ceramic foams
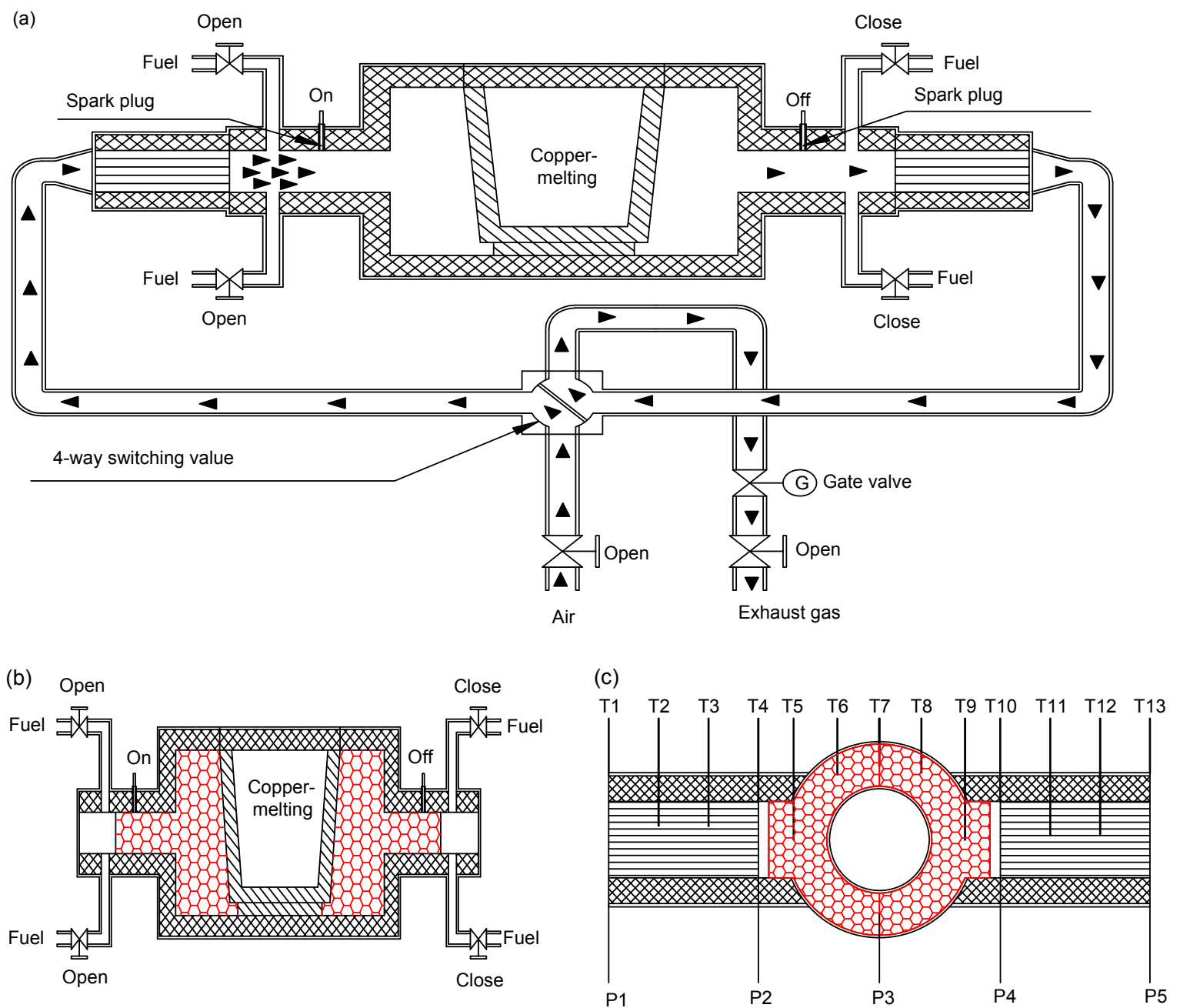

Fig. 1 Schematic diagram of the experimental burner test apparatus

(a) $125 \mathrm{~kW}$ reciprocal copper melting industrial furnace; (b) Developed PRTO; (c) Arrangement of thermocouples T1-T13 and pressure taps $\mathrm{P} 1-\mathrm{P} 5$

(a)

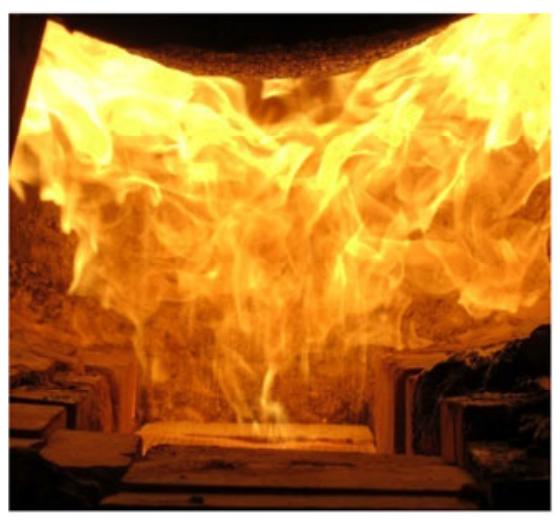

(b)

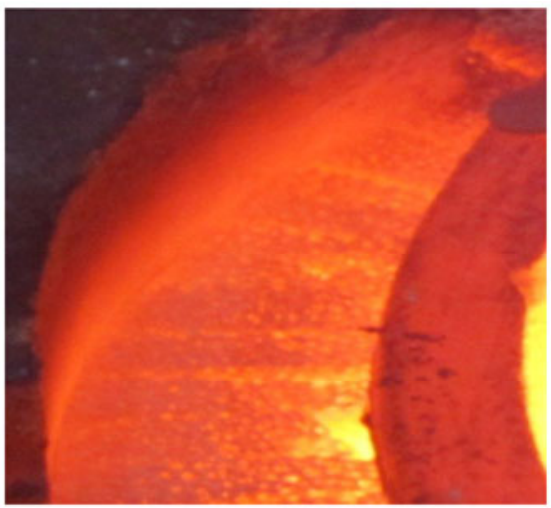

Fig. 2 Flame images of free flame of RTO (a) and filtration combustion flame of PRTO (b) 
Fig. 2b. The copper inside the crucible was heated by the convection and radiation heat emanating from the $\mathrm{ZrO}_{2}$ porous medium. In addition, the newly developed burner can act as a reciprocal flow burner when there are non-premixed combustion conditions.

\subsection{Control system and measurements}

Fresh air was generated by a centrifugal fan and entered through an alternating valve. Natural gas with a heating value of $36 \mathrm{MJ} / \mathrm{N} \cdot \mathrm{m}^{3}$ was used and controlled by valves mounted on the control panel. The gas and airflow rates were measured by calibrated rotameters. The time intervals in-between each flow could be adjusted independently using a switch. The arrangement of thermocouples and pressure taps are shown in Fig. 1c. B-type model T5-T9 sheath thermocouples with a $0.5 \mathrm{~mm}$ wire diameter and K-type T1-T4 as well as T10-T13 thermocouples were used. They were placed along the center line of the fluid path to measure the temperature profiles. Pressure differences were measured by differential pressure transmitters P1-P5, and their signals were digitized by an Agilent-34970a Data Logger (USA) and then transmitted to a personal computer. The combustion emission levels were analyzed by a TESTO PG-250 instrument with a range of $0-0.1 \%$ and $0-0.4 \%$ for $\mathrm{NO}_{x}$ and $\mathrm{CO}$, respectively, with a measuring accuracy of about $\pm 0.5 \%$.

\subsection{Procedure}

During an operation cycle of $150 \mathrm{~s}$, the two fuel nozzles on the left were open so that the left burner worked in the combustion mode and the two fuel nozzles on the right were closed so that the right burner worked in the suction mode. Then the operating mode was reversed in the following cycle so that the right burner was in the combustion mode and the left was in suction. The combustion air was preheated by the heat accumulated in the ceramic honeycomb during the previous cycle. The interchange between burners was controlled by the 4-way switching value during the entire melting process. The copper-melting process can be divided into two stages: (1) start-up stage where the burner was preheated starting from the cold state, and (2) quasi-steady stage where the furnace wall and crucible have been heated to a quasisteady state. In the preheating period, the thermal load needs to reach a temperature where it is possible for copper-fusion. Numerical values of the operating conditions are summarized in Table 1.

Table 1 Operating conditions

\begin{tabular}{ll}
\hline \multicolumn{1}{c}{ Quantity } & Value \\
\hline Bed height, $H(\mathrm{~m})$ & 4.3 \\
Bed width, $W(\mathrm{~m})$ & 1.6 \\
Bed length, $L(\mathrm{~m})$ & 1.6 \\
Inlet gas temperature, $T_{\mathrm{g}}(\mathrm{K})$ & 303 \\
Heating value of $\mathrm{CH}_{4}\left(\mathrm{MJ} / \mathrm{N} \cdot \mathrm{m}^{3}\right)$ & 36 \\
Copper-melting rate $(\mathrm{kg} / \mathrm{h})$ & $0-750$ \\
Heat input $(\mathrm{kW})$ & 125 \\
Equivalence ratio, $\Phi$ & $0.3-0.5$ \\
Half-period, $t_{\mathrm{hp}}(\mathrm{s})$ & 150 \\
Ceramic foam properties & \\
Porous materials & $\mathrm{ZrO} 2$ \\
Porosity & 0.84 \\
Pore size & $10 \mathrm{PPI}_{2}$ \\
Honeycomb properties & \\
Porous materials & $>70 \% \mathrm{Al}_{2} \mathrm{O}_{3}$, \\
Porosity & $>20 \% \mathrm{SiO}_{2}$ \\
Pore size & 0.5 \\
\hline
\end{tabular}

\subsection{Thermal efficiency methodology}

There is a lack of standard procedures for measuring the radiant efficiency in different burner designs and operation conditions (Mital et al., 1998). Therefore, a thermal efficiency methodology was developed where the parameters such as heat input, thermal absorption by copper, and thermal efficiency were estimated.

The energy input of the burner is

$$
Q_{\mathrm{in}}=V_{\mathrm{g}} H_{\mathrm{g}} t
$$

where $V_{\mathrm{g}}$ is the volumetric flow rate of natural gas in $\mathrm{N} \cdot \mathrm{m}^{3} / \mathrm{s}, H_{\mathrm{g}}$ is the heating value of natural gas in $\mathrm{kJ} /\left(\mathrm{N} \cdot \mathrm{m}^{3}\right)$, and $t$ is the time needed for the copper to melt in $\mathrm{s}$.

The useful energy absorbed by copper can be calculated by

$$
Q_{\mathrm{useful}}=m_{\mathrm{cp}} C_{\mathrm{cp}}\left(T_{\mathrm{cp}}-T_{0}\right),
$$

where $m_{\mathrm{cp}}$ is the mass of copper in $\mathrm{kg}, C_{\mathrm{cp}}$ is the 
heating capacity of copper in $\mathrm{kJ} /(\mathrm{kg} \cdot \mathrm{K}), T_{\mathrm{cp}}$ is the melting point of copper in $\mathrm{K}$, and $T_{0}$ is the initial temperature of copper in $\mathrm{K}$.

Then the thermal efficiency is expressed as follows:

$$
\eta_{\mathrm{th}}=Q_{\text {useful }} / Q_{\mathrm{in}} \times 100 \% \text {. }
$$

\section{Results and discussion}

\subsection{Pressure drop}

Fig. 3 shows the pressure drops during the start-up procedure at an equivalence ratio of $\Phi=0.4$. $\triangle \mathrm{P} 1 \mathrm{P} 2$ and $\triangle \mathrm{P} 4 \mathrm{P} 5$ are the pressure drops between the regenerators, while $\triangle \mathrm{P} 2 \mathrm{P} 3$ and $\triangle \mathrm{P} 3 \mathrm{P} 4$ are the pressure drops between the porous media combustors. Due to the pressure drop in the RTO being mainly composed of the regenerators, it was possible to use the sum of $\triangle \mathrm{P} 1 \mathrm{P} 2$ and $\triangle \mathrm{P} 4 \mathrm{P} 5$ from the PRTO's start-up procedure to represent the RTO's pressure drop. Both the pressure drops increase as the time for the gas velocity increases due to the furnace temperature (T7) rising. However, the growth rate of PRTO was much larger than that of RTO. The sum of the pressure drop in the PRTO $(\triangle \mathrm{P} 1 \mathrm{P} 5)$ in the final hot stage was near $1000 \mathrm{~Pa}$; whereas the whole pressure drop in $\mathrm{RTO}(\Delta \mathrm{P} 1 \mathrm{P} 2+\Delta \mathrm{P} 4 \mathrm{P} 5)$ was less than $200 \mathrm{~Pa}$. Therefore, a much more powerful centrifugal fan would be needed to bring about a higher pressure drop.

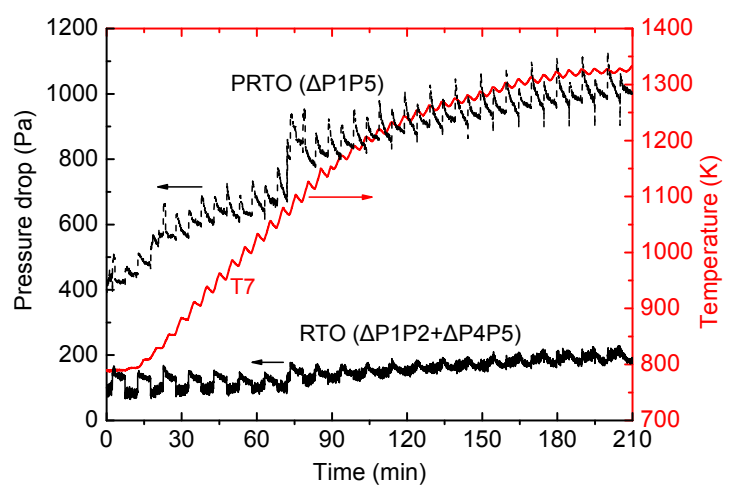

Fig. 3 Pressure drops during the start-up procedures

\subsection{Temperature distribution}

Fig. 4 shows the temperature distribution comparison for copper melting between the RTO and
PRTO systems at an equivalence ratio of $\Phi=0.4$. The temperature distributions for both the RTO system and the PRTO system are the values at the first of the forward flow. The porous media had high temperature region that was broader than in the RTO while the maximum temperature was lower. For instance, the maximum temperature under an equivalence ratio of $\Phi=0.4$ drops from $1804 \mathrm{~K}$ (in the free flame of the RTO system) to $1598 \mathrm{~K}$ (in the filtration flame of the PRTO system). However, there is a larger hot zone due to the heat conduction of the porous material.

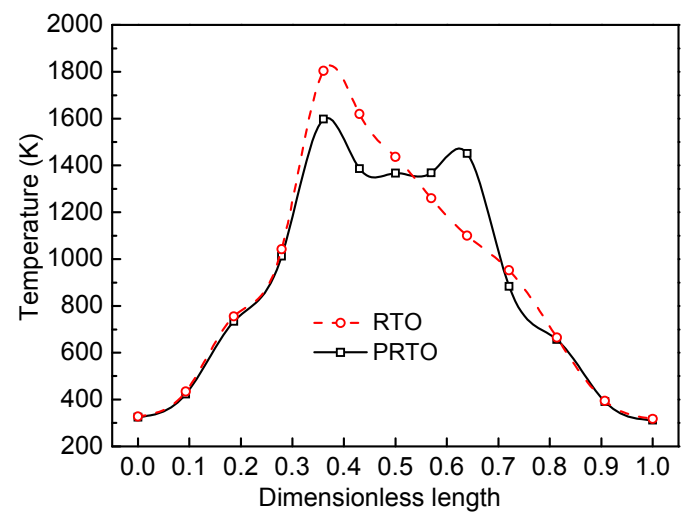

Fig. 4 Comparison of temperature distribution between the RTO and PRTO systems

Fig. 5 shows the special transient temperature profiles of the PRTO system for the forward flow during a half-period of $t_{\mathrm{hp}}=150 \mathrm{~s}$ under an equivalence ratio of $\Phi=0.4$. The trapezoidal temperature profiles have two hot zone locations at the inlet of the porous media combustor (e.g., T5 and T9); while the temperatures in the crucible zone (e.g., T6, T7, and T8) are relatively low (about $200 \mathrm{~K}$ on average). The peak temperature changes moderately over time within a range of $160 \mathrm{~K}$, while the temperatures in the crucible zone are almost flat irrespective of time. The thermal efficiency and energy saving are greatly improved due to the exhaust gas temperatures (e.g., T1 and T13) being greatly reduced (within $310-330 \mathrm{~K}$ ).

\subsection{Exhaust gas emissions}

The exhaust gas emissions from both the RTO and PRTO systems were measured, and the results were corrected to $6 \% \mathrm{O}_{2}$. The $\mathrm{CO}$ and $\mathrm{NO}_{x}$ emission levels at different equivalence ratios are shown in Fig. 6. As the equivalence ratios increased, so did the emissions of $\mathrm{CO}$ and $\mathrm{NO}_{x}$ due to the peak temperature 
increasing along with the equivalence ratio, which also results in increased incomplete combustion of the natural gas.

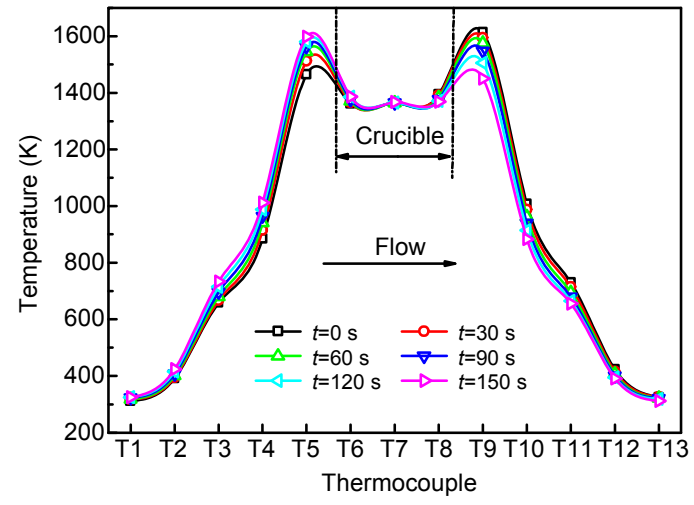

Fig. 5 Transient temperature profiles of the PRTO system for the forward flow during a half-period of $t_{\mathrm{hp}}=150 \mathrm{~s}$

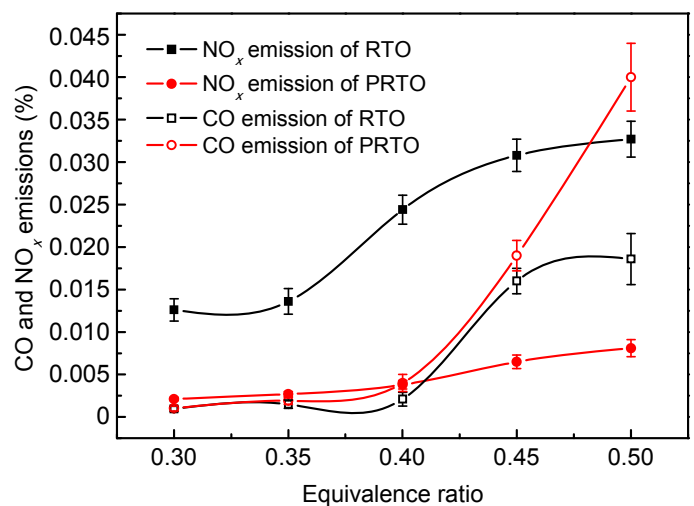

Fig. 6 Comparison of $\mathrm{CO}$ and $\mathrm{NO}_{x}$ emissions between the RTO and PRTO systems

As shown in Fig. 6, for the same equivalence ratio, the amount of $\mathrm{NO}_{x}$ produced is significantly lower when the porous medium is inserted. This is caused by the use of the porous medium that results in a reduced maximum temperature. For instance, the $\mathrm{NO}_{x}$ emission at an equivalence ratio of $\Phi=0.5$ drops from $0.0327 \%$ for the RTO system to $0.0081 \%$ for the PRTO system. This level of $\mathrm{NO}_{x}$ emission is slightly greater than those obtained by previous researchers using premixed combustion, such as Jugjai and Sawananon (2004), who obtained an emission range of $0.001 \%-0.004 \%$ for $\mathrm{NO}_{x}$. However, for lean combustion at an equivalence ratio $\Phi<0.4$, the $\mathrm{NO}_{x}$ emission has a range of $0.002 \%-0.003 \%$. In contrast, the $\mathrm{CO}$ emissions from the PRTO system were greater than those from the RTO system; the differences in the emissions levels were particularly marked in the high equivalence ratio regimes. The existence of the porous medium decreased the extent of mixing between the fuel and oxidizer. However, very similar levels of CO emissions $(0.001 \%-0.002 \%)$ were observed under an equivalence ratio of $\Phi<0.4$. This indicated that the non-premixed methane combustion in the PRTO system is mostly suitable for the lean combustion process under an equivalence ratio $\Phi<<0.4$.

\subsection{Thermal efficiency}

Thermal efficiency is the key parameter for evaluating the economic benefits of burners. The comparison of thermal efficiencies between the RTO and PRTO systems is shown in Fig. 7. Due to the honeycombs and ceramic foams requiring additional preheating, the thermal efficiency was much lower in the start-up stage than the quasi-steady stage.

As shown in Fig. 7, for the PRTO system, when compared to the RTO system, the thermal efficiency was lower during the start-up stage but significantly higher in the quasi-steady stage. This is attributed to the fact that the heat storage in the porous media reduces the thermal efficiency in the start-up stage; while the combined effect of the convection and radiation process by the porous medium increases the thermal efficiency in the quasi-steady stage. The transient temperature profiles of the PRTO system during the start-up procedure are shown in Fig. 8. For the PRTO system to reach the quasi-steady stage from a cold state took around $2.5 \mathrm{~h}$, but in the RTO system it took slightly less than $2 \mathrm{~h}$. However, the thermal efficiency in the quasi-steady stage increases by about $30 \%$ relative to RTO system and reaches a value of $37.5 \%$. For a continuous combustion operation, the

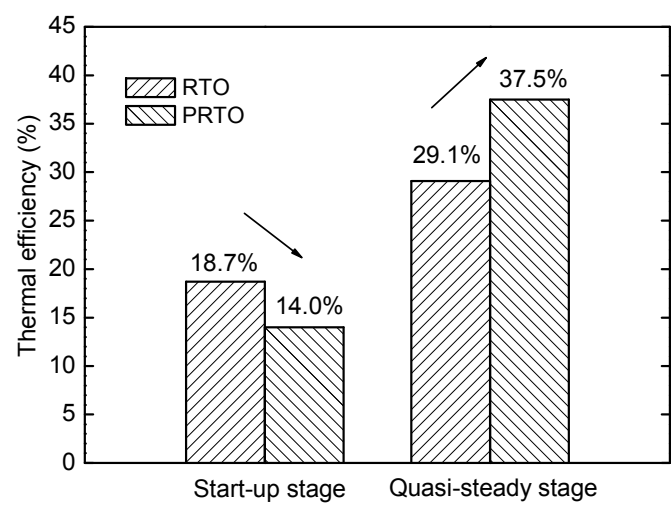

Fig. 7 Comparison of thermal efficiencies between the RTO and PRTO systems 
technology using a PRTO system is undoubtedly more effective compared to the RTO system (Fig. 7).

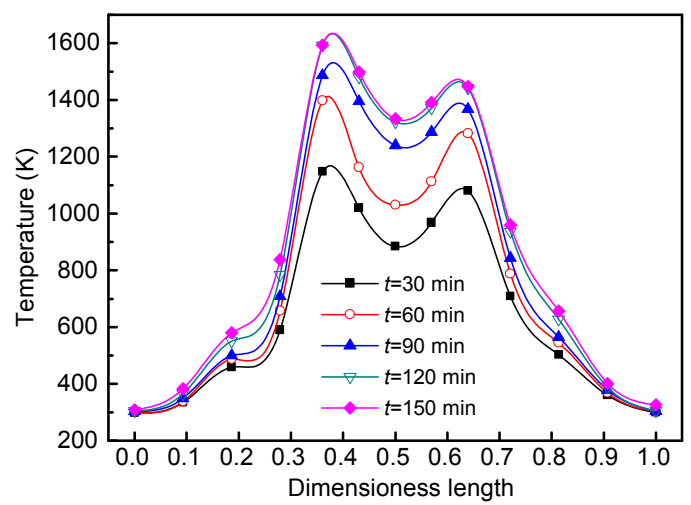

Fig. 8 Transient temperature profiles of PRTO system during the start-up procedure

\section{Conclusions}

A PRTO system under reciprocating flow conditions using non-premixed $\mathrm{CH}_{4}$ combustion has been successfully developed for a $125 \mathrm{~kW}$ industrial copper-melting furnace. The combustion and emission characteristics were evaluated and compared to a conventional RTO system. It was found that the high temperature region in the porous media is broader while its maximum temperature range is thinner resulting in a significantly lower $\mathrm{NO}_{x}$ emission level. For lean combustion processes under an equivalence ratio of $\Phi<0.4$, the $\mathrm{CO}$ and $\mathrm{NO}_{x}$ emission levels were in the ranges of $0.001 \%-0.002 \%$ and $0.002 \%$ $0.003 \%$, respectively. This means that fuel savings of approximately $30 \%$ can be achieved during the quasi-steady state when using the PRTO system instead of the RTO system. However, a much more powerful centrifugal fan is needed due to a higher pressure drop in the system. More work is still needed to improve the mixing of the fuel and oxidizer as when there is a higher equivalence ratio regime the $\mathrm{CO}$ emission level was slightly higher.

\section{References}

Charoensuk, J., Lapirattanakun, A., 2011. On flame stability, temperature distribution and burnout of air-staged porous media combustor firing LPG with different porosity and excess air. Applied Thermal Engineering, 31(16):31253141. [doi:10.1016/j.applthermaleng.2011.04.042]

Dobrego, K.V., Kozlov, I.M., Zhdanok, S.A., Gnesdilov, N.N.,
2001. Modeling of diffusion filtration combustion radiative burner. International Journal of Heat and Mass Transfer, 44(17):3265-3272. [doi:10.1016/S0017-9310 (00)00343-4]

Howell, J.R., Hall, M.J., Ellzey, J.L., 1996. Combustion of hydrocarbon fuels within porous inert media. Progress in Energy and Combustion Science, 22(2):121-145. [doi:10. 1016/0360-1285(96)00001-9]

Jugjai, S., Sawananon, A., 2004. The surface combustor-heater with cyclic flow reversal combustion embedded with water tube bank. Fuel, 83(17-18):2369-2379. [doi:10.1016/ j.fuel.2004.06.026]

Kamal, M.M., Mohamad, A.A., 2005. Enhanced radiation output from foam burners operating with a nonpremixed flame. Combustion and Flame, 140(3):233-248. [doi:10. 1016/j.combustflame.2004.12.001]

Kamal, M.M., Mohamad, A.A., 2006. Combustion in porous media. Proceedings of the Institution of Mechanical Engineers, Part A: Journal of Power and Energy, 220(5): 487-508. [doi:10.1243/09576509JPE169]

Li, G.N., Zhou, H., Cen, K.F., 2008. Emission characteristics and combustion instabilities in an oxy-fuel swirl-stabilized combustor. Journal of Zhejiang University-SCIENCE A. 9(11):1582-1589. [doi:10.1631/jzus.A0820303]

Masashi, K., Toshiaki, H., 1998. The Scientific and Technology of Combustion Highly Preheated Air. 27th Symposium (International) on Combustion/The Combustion Institute, 27(2):3135-3146. [doi:10.1016/S0082-0784(98)80176-8]

Mathis, W.M., Ellzey, J.L., 2005. Flame stabilization, operating range, and emissions for a methane/air porous burner. Combustion Science and Technology, 177(5):1323-1338. [doi:10.1080/00102200302411]

Michael, F., 2001. Low $\mathrm{NO}_{x}$ combustion technologies for high temperature applications. Energy Conversion and Management, 42(15):1919-1935. [doi:10.1016/S0196-8904 (01)00051-6]

Mital, R., Gore, J.P., Viskanta, R., 1998. A radiation efficiency measurement procedure for gas-fired radiant burners. Experimental Heat Transfer, 11(1):3-21. [doi:10.1080/ 08916159808946551]

Muhad, R.M.N., Abdullah, M.Z., Mujeebu, M.A., Bakar, M.A.A., Zakaria, R., Mohamad, A.A., 2011. The development and performance analysis of partially premixed LPG porous medium combustor. Energy Sources, Part A: Recovery, Utilization, and Environmental Effects, 33(13): 1260-1270. [doi:10.1080/15567030903330827]

Mujeebu, M.A., Abdullah, M.Z., Bakar, M.A.A., Mohamad, A.A., Abdullah, M.K., 2009a. Applications of porous media combustion technology-review. Applied Energy, 86(9):1365-1375. [doi:10.1016/j.apenergy.2009.01.017]

Mujeebu, M.A., Abdullah, M.Z., Bakar, M.A.A., Mohamad, A.A., Muhad, R.M.N., Abdullah, M.K., 2009b. Combustion in porous media and its applications-A comprehensive survey. Journal of Environmental Management, 90(8):2287-2312. [doi:10.1016/j.jenvman.2008.10.009]

Mujeebu, M.A., Abdullah, M.Z., Bakar, M.A.A., Mohamad, 
A.A., 2011. A mesoscale premixed LPG burner with surface combustion in porous ceramic foam. Energy Sources, Part A: Recovery, Utilization, and Environmental Effects, 34(1):9-18. [doi:10.1080/15567030903515062]

Wood, S., Harris, A.T., 2008. Porous burners for lean-burn applications. Progress in Energy and Combustion Science, 34(5):667-684. [doi:10.1016/j.pecs.2008.04.003]

Smucker, M.T., Ellzey, J.L., 2004. Computational and experimental study of a two-section porous burner. Combustion Science and Technology, 176(8):1171-1189. [doi:10.1080/00102200490457385]

Suzukawa, Y., Sugiyama, S., Hino, Y., Ishioka, M., Mori, I., 1997. Heat transfer improvement and $\mathrm{NO}_{x}$ reduction by highly preheated air combustion. Energy Conversion and Management, 38(10-13):1061-1071. [doi:10.1016/S01968904(96)00136-7]

Tarokh, A., Mohamad, A.A., 2009. Non-premixed $\mathrm{CH}_{4}$ Combustion in a Porous Media. Proceedings of the ASME International Mechanical Engineering Congress \& Exposition, Florida, USA.

Wang, G., Luo, D., Huang, H., Huang, X.F., Xu, J.R., 2011. Characteristics on Temperature Profiles of No-premixed Combustion in Porous Media. Power and Energy Engineering Conference (APPEEC), Asia-Pacific. Wuhan, China, p.1-4. [doi:10.1109/APPEEC.2011.5748652] 